\title{
HIV testing trends among gay men in Scotland, UK (1996-2005): implications for HIV testing policies and prevention
}

\author{
L M Williamson, ${ }^{1}$ P Flowers, ${ }^{2} \mathrm{C}$ Knussen, ${ }^{2} \mathrm{G}$ J Hart ${ }^{3}$
}

\section{See Editorial, p 487}

${ }^{1}$ MRC Social and Public Health Sciences Unit, Glasgow, UK;

${ }^{2}$ Division of Psychology, School of Life Sciences, Glasgow Caledonian University, Glasgow, UK; ${ }^{3}$ Centre for Sexual Health and HIV Research, Research Department of Infection and Population Health, University College London, London, UK

Correspondence to:

Dr L M Williamson, MRC Social and Public Health Sciences Unit, 4 Lilybank Gardens, Glasgow G12 8RZ, UK; Lisa@sphsu.mrc. ac.uk

Accepted 26 February 2009 Published Online First

9 March 2009

\section{UNIOCKED}

This paper is freely available online under the BMJ Journals unlocked scheme, see http:// sti.bmj.com/info/unlocked.dtl

\section{ABSTRACT}

Objective: To examine trends in the HIV testing behaviour of gay men in Scotland over a 10-year period. Methods: Seven cross-sectional surveys in commercial gay venues in Glasgow and Edinburgh (1996-2005). 9613 men completed anonymous, self-completed questionnaires (70\% average response rate).

Results: Among 8305 respondents included in these analyses, HIV testing increased between 1996 and 2005, from $49.7 \%$ to $57.8 \%(p<0.001)$. The proportion of men who had tested recently (in the calendar year of, or immediately before, the survey) increased from $28.4 \%$ in 1996 to $33.2 \%$ in 2005, when compared with those who have tested but not recently, and those who have never tested (adjusted odds ratio $1.31,95 \% \mathrm{Cl} 1.13$ to 1.52 ). However, among ever testers, there was no increase in rates of recent testing. Recent testing decreased with age: $31.3 \%$ of the under $25,30.3 \%$ of the $25-34,23.2 \%$ of the $35-44$ and $21.2 \%$ of the over 44 years age groups had tested recently. Among men reporting two or more unprotected anal intercourse partners in the previous year, only $41.4 \%$ had tested recently.

Conclusions: HIV testing among gay men in Scotland increased between 1996 and 2005, and corresponds with the Scottish Government policy change to routine, opt-out testing in genitourinary medicine clinics. Testing rates remain low and compare unfavourably with near-universal testing levels elsewhere. The limited change and decline across age groups in recent HIV testing rates suggest few men test repeatedly or regularly. Additional, innovative efforts are required to increase the uptake of regular HIV testing among gay men.

Increases in HIV incidence among men who have sex with men (MSM) have been reported, ${ }^{1}$ and MSM remain the group most at risk of acquiring HIV in the UK. ${ }^{2}$ In Scotland, MSM account for $36 \%$ of HIV diagnoses, and current HIV prevalence in this group is $4.3 \%{ }^{3}$ In 2005 , community-based surveys of gay men in Scotland found $42 \%$ of HIVpositive men were undiagnosed, ${ }^{4}$ compared with $30 \%$ of MSM genitourinary medicine (GUM) clinic attenders, but recent estimates suggest less than $10 \%$ remain undiagnosed following a clinic attendance. ${ }^{3}$ This has been credited to the introduction of routine, opt-out testing in GUM clinics, whereby all patients should be offered an HIV test regardless of symptoms or risk factors. This was implemented as part of the Scottish sexual health strategy, ${ }^{5}$ which was distinct from the strategy for England and Wales. ${ }^{6}$ This policy is now recommended throughout the UK. ${ }^{7}$
The promotion of regular and frequent HIV antibody testing as a means of identifying, and therefore limiting, the potential onward transmission of infection is a core component of prevention efforts in the USA and the Centers for Disease Control and Prevention recently recommended routine HIV testing should be performed in all healthcare settings. ${ }^{8}$ In the UK, HIV testing has traditionally played a lesser part in prevention efforts but its promotion has been central to recent campaigns (see, for example, http://www.hivcomebacktour.co.uk/). The UK Chief Medical Officer recently advocated extension of this to all healthcare settings, ${ }^{9}$ and the 2008 UK national guidelines for HIV testing are designed to facilitate this. ${ }^{7}$ However, HIV testing rates among gay men in Scotland have traditionally been lower than among men in similar surveys elsewhere in the UK and Europe,$^{10}{ }^{11}$ and compare unfavourably with the near universal rates reported in the USA and Australia. ${ }^{12} 13$ In this paper, we examine trends in the HIV testing behaviour of gay men in Scotland over a 10-year period, and discuss whether we are doing enough to promote testing in the group most at risk of acquiring HIV in Scotland.

\section{METHODS}

We conducted seven cross-sectional surveys between 1996 and 2005 in commercial gay venues in Glasgow and Edinburgh (table 1).. ${ }^{44-16}$ Time and location sampling was used to recruit representative samples. All seven surveys utilised anonymous, self-completed questionnaires and respondents were asked whether they had ever had an HIV test and for the date of their most recent test. Those tested in the year of the survey, or the year immediately before it, were categorised as recent HIV testers (eg, for the 2005 survey, men testing in 2005 or 2004 were categorised as recent testers).

Ethics approval was granted for the 1996, 1999, 2002a, and 2005 surveys by the University of Glasgow Ethics Committees for Non-clinical Research Involving Human Subjects, and for the 2000 survey by the Psychology Ethics Committee at Glasgow Caledonian University. The 2002b and 2003 surveys were exact replications of the 2000 study design and methodology. Consequently no further ethics approval for these surveys was sought.

The data were analysed by $\chi^{2}$ tests and logistic regression. The analysis was conducted using SPSS 16.0 for Mac.

\section{RESULTS}

Questionnaires were obtained from 9613 men with an average response rate of $70 \%$ (table 1 ). Men 
Table 1 Survey year, source, location and numbers approached, participating and included in the analyses

\begin{tabular}{llllllc}
\hline $\begin{array}{l}\text { Year of } \\
\text { survey }\end{array}$ & Source & Location & $\begin{array}{l}\text { Number } \\
\text { approached }\end{array}$ & $\begin{array}{l}\text { Number } \\
\text { participating } \\
\text { (N = 9613) }\end{array}$ & $\begin{array}{l}\text { Response rate } \\
\text { (\%) }\end{array}$ & $\begin{array}{l}\text { Number } \\
\text { included in } \\
\text { analyses } \\
\text { (N = 8305)* }\end{array}$ \\
\hline 1996 & MRC & Edinburgh/Glasgow & 2881 & 2276 & 79 & 2097 \\
1999 & MRC & Edinburgh/Glasgow & 3202 & 2498 & 78 & 2125 \\
2000 & HGS & Edinburgh/Glasgow & 1029 & 803 & 78 & 652 \\
$2002^{\text {a }}$ & MRC & Edinburgh/Glasgow & 2796 & 1734 & 62 & 1468 \\
$2002^{\text {b }}$ & GMH & Edinburgh & 456 & 283 & 62 & 262 \\
2003 & GMH & Edinburgh & 429 & 275 & 64 & 230 \\
2005 & MRC & Edinburgh/Glasgow & 2642 & 1744 & 66 & 1471 \\
\hline
\end{tabular}

*Those who responded to all of the following questions: age, ever had HIV test, date of last HIV test and numbers of unprotected anal intercourse partners in the previous year. GMH, Gay Men's Health; HGS, Healthy Gay Scotland; MRC, Medical Research Council.

responding to the question on HIV testing, and who also provided information on age, date of last HIV test and numbers of unprotected anal intercourse (UAI) partners in the previous year, are included in the analysis $(\mathrm{N}=8305)$. The age breakdown of each survey is shown in table 2 .

Overall, 4370 respondents (52.6\%) reported that they had had an HIV test. The proportion reporting they had ever had an HIV test increased between 1996 and 2005, from 49.7\% to 57.8\% $(p<0.001)$. Table 3 shows the proportions who reported having a recent test (in the calendar year of, or immediately before, the survey), having ever, but not recently, tested (within $>1-5$ and $6+$ years ago) and having never tested by age group and year of survey. Although the proportion who reported recent testing increased from $28.4 \%$ in 1996 to $33.2 \%$ in 2005 (reaching their highest level of $40.4 \%$ in 2003), the proportion tested over 15 years ago varied slightly over the seven surveys but remained at $15 \%$ in 1996 and 2005, and the proportion tested more than 6 years ago increased from $6.2 \%$ in 1996 to $9.6 \%$ in 2005 . The odds ratios for recent testing (compared with those who have tested but not recently and those who have never tested), adjusted for age, are shown in table 3. Compared with 1996, the odds ratios associated with recent testing for the 1999 and 2002a surveys were somewhat lower $(p=0.003$ and $p=0.038$, respectively), whereas the odds ratio for the 2000 survey did not differ significantly from that associated with 1996. However, the odds ratios for the 2002b, 2003 and 2005 surveys were all significantly higher $($ all $\mathrm{p}<0.01)$, indicating that recent testing rates in these years were higher than those recorded in 1996.

However, recency of testing among those who reported having had an HIV test at some point in their lives varied but there was no real increase over time, falling from 57.1\% (595/ 1042 ) in 1996 to $48.2 \%$ (369/766) in $2002 \mathrm{a}$ and rising to $57.5 \%$ (488/850) in 2005. The adjusted odds ratios (AOR) for recent testing compared with those who had ever, but not recently, tested (excluding those who have never tested) were also calculated. Compared with 1996, the odds ratios were significantly different (lower) in the 1999 (AOR 0.79, 95\% CI 0.62 to 0.89 ) and $2002 \mathrm{a}$ (AOR 0.69 , 95\% CI 0.57 to 0.84 ) surveys. However, the odds ratios were not significantly different in the 2002 b (AOR 1.16, 95\% CI 0.81 to 1.65), 2003 (AOR 1.17, 95\% CI 0.83 to 1.65 ) or 2005 (AOR 1.10, 95\% CI 0.91 to 1.33) surveys. This indicates that among men who had had an HIV test, there was no increase in rates of recent testing between 1996 and 2005.

Although the proportion of men who had never had an HIV test decreased with age between the under 25, 25-34 and 3544 years age groups, the proportion tested recently also decreased with age. On average, $31.3 \%$ of the under $25,30.3 \%$ of the $25-34,23.2 \%$ of the $35-44$ and $21.2 \%$ of the over 44 years age groups had tested recently. Table 3 shows the pattern of change over time for each age group. Among the under 25 years age group, recent testing fell from 33.9\% in 1996 to $26.9 \%$ in $2002 \mathrm{a}$ and rose to $34.2 \%$ in 2005 (with a high of $51.1 \%$ in the Edinburgh-only 2003 survey). Among the 25-34 years age group, recent testing increased from $29.7 \%$ in 1996 to $41.4 \%$ in 2005. In the 35-44 years age group, recent testing rose from $22.4 \%$ in 1996 to $39.0 \%$ in 2003 and fell to $26.0 \%$ in 2005 . In the over 44 years age group, the proportions tested recently varied over time, rising from $20.4 \%$ in 1996 to $24.4 \%$ in 2005 .

Aggregate rates of recent HIV testing were consistently higher among men who reported two or more UAI partners in the previous year than among men who reported none or one partner (AOR 1.93, 95\% CI 1.68 to 2.23; table 4). Overall, $41.4 \%$ of men reporting UAI with two or more partners had tested recently. Among men who reported UAI with two or more partners, recent testing was lowest in the 35-44 year age group, with only $34.2 \%$ having had a recent test.

\section{DISCUSSION}

Rates of self-reported HIV testing increased among gay men in Scotland surveyed in commercial venues between 1996 and

Table 2 Age of respondents by year of survey $(\mathrm{N}=8305)$

\begin{tabular}{llllllll}
\hline \multicolumn{7}{c}{ Year of survey } \\
\cline { 2 - 8 } & $\mathbf{1 9 9 6}$ & $\mathbf{1 9 9 9}$ & $\mathbf{2 0 0 0}$ & $\mathbf{2 0 0 2 a}$ & $\mathbf{2 0 0 2 b}$ & $\mathbf{2 0 0 3}$ & $\mathbf{2 0 0 5}$ \\
& $\mathbf{N = 2 0 9 7}$ & $\mathbf{N = 2 1 2 5}$ & $\mathbf{N = 6 5 2}$ & $\mathbf{N}=\mathbf{1 4 6 8}$ \\
$\mathbf{N}(\%)$ & $\mathbf{n}(\%)$ & $\mathbf{n}(\%)$ & $\mathbf{n}(\%)$ & $\mathbf{n}(\%)$ & $\begin{array}{l}\mathbf{N}=230 \\
\mathbf{n}(\%)\end{array}$ & $\begin{array}{l}\mathbf{N}=\mathbf{1 4 7 1} \\
\mathbf{n}(\%)\end{array}$ \\
\hline Age group, years & & & & & & & \\
$<25$ & $475(22.7)$ & $479(22.5)$ & $173(26.5)$ & $438(29.8)$ & $82(31.3)$ & $43(18.7)$ & $400(27.2)$ \\
$25-34$ & $1010(48.2)$ & $942(44.3)$ & $263(40.3)$ & $567(38.6)$ & $96(36.6)$ & $77(33.5)$ & $488(33.2)$ \\
$35-44$ & $455(21.7)$ & $504(23.7)$ & $161(24.7)$ & $366(24.9)$ & $63(24.0)$ & $77(33.5)$ & $407(27.7)$ \\
$>44$ & $157(7.5)$ & $200(9.4)$ & $55(8.4)$ & $97(6.6)$ & $21(8.0)$ & $33(14.3)$ & $176(12.0)$ \\
\hline
\end{tabular}


Table 3 HIV testing by year of survey and age of respondents $(\mathrm{N}=8305)$

\begin{tabular}{|c|c|c|c|c|c|c|c|}
\hline & \multicolumn{7}{|c|}{ Year of survey } \\
\hline & $\begin{array}{l}1996 \\
N=2097 \\
n(\%)\end{array}$ & $\begin{array}{l}1999 \\
N=2125 \\
n(\%)\end{array}$ & $\begin{array}{l}2000 \\
N=652 \\
n(\%)\end{array}$ & $\begin{array}{l}2002 a \\
N=1468 \\
n(\%)\end{array}$ & $\begin{array}{l}2002 b \\
N=262 \\
n(\%)\end{array}$ & $\begin{array}{l}2003 \\
N=230 \\
n(\%)\end{array}$ & $\begin{array}{l}2005 \\
N=1471 \\
n(\%)\end{array}$ \\
\hline \multicolumn{8}{|l|}{$<25$ Years } \\
\hline Recent HIV test ${ }^{*}$ & 161 (33.9) & $127(26.5)$ & $57(32.9)$ & $118(26.9)$ & $33(40.2)$ & $22(51.1)$ & $137(34.2)$ \\
\hline Last tested $>1-5$ years ago & $40(8.4)$ & $49(10.2)$ & $12(6.9)$ & $50(11.4)$ & $4(4.9)$ & $3(7.0)$ & $31(7.8)$ \\
\hline \multicolumn{8}{|l|}{ 25-34 Years } \\
\hline Recent HIV test* & $300(29.7)$ & $245(26.0)$ & $71(27.0)$ & $155(27.3)$ & $37(38.5)$ & $32(41.6)$ & $202(41.4)$ \\
\hline Last tested $>1-5$ years ago & $179(17.7)$ & $194(20.6)$ & $66(25.1)$ & $131(23.1)$ & $20(20.8)$ & $17(22.1)$ & $78(16.0)$ \\
\hline Last tested $6+$ years ago & $68(6.7)$ & $62(6.6)$ & $17(6.5)$ & $43(7.6)$ & $7(7.3)$ & $7(9.1)$ & $27(5.5)$ \\
\hline Never had HIV test & $463(45.8)$ & $441(46.8)$ & $109(41.4)$ & $238(42.0)$ & $32(33.3)$ & $21(27.3)$ & $181(37.1)$ \\
\hline Never had HIV test & $232(51.0)$ & $233(46.2)$ & $70(43.5)$ & $148(40.4)$ & $19(30.2)$ & $15(19.5)$ & $141(34.6)$ \\
\hline \multicolumn{8}{|l|}{$>44$ Years } \\
\hline Recent HIV test* ${ }^{*}$ & $32(20.4)$ & $37(18.5)$ & $9(16.4)$ & $20(20.6)$ & $7(33.3)$ & $9(27.3)$ & $43(24.4)$ \\
\hline Last tested $>1-5$ years ago & $25(15.9)$ & $30(15.0)$ & $5(9.1)$ & $15(15.5)$ & $2(9.5)$ & $8(24.2)$ & $26(14.8)$ \\
\hline Last tested $6+$ years ago & $10(6.4)$ & $31(15.5)$ & $13(23.6)$ & $16(16.5)$ & $4(19.0)$ & $4(12.1)$ & $34(19.3)$ \\
\hline Never had HIV test & $90(57.3)$ & $102(51.0)$ & $28(50.9)$ & $46(47.4)$ & $8(38.1)$ & $12(36.4)$ & $73(41.5)$ \\
\hline \multicolumn{8}{|l|}{ Total } \\
\hline Recent HIV test ${ }^{*}$ & $595(28.4)$ & $511(24.0)$ & $175(26.8)$ & $369(25.1)$ & $95(36.3)$ & $93(40.4)$ & $488(33.2)$ \\
\hline Last tested $>1-5$ years ago & $318(15.2)$ & $382(18.0)$ & $112(17.2)$ & $280(19.1)$ & $41(15.6)$ & $44(19.1)$ & $221(15.0)$ \\
\hline Last tested $6+$ years ago & $129(6.2)$ & $156(7.3)$ & $54(8.3)$ & $117(8.0)$ & $22(8.4)$ & 27 (11.7) & $141(9.6)$ \\
\hline Never had HIV test & $1055(50.3)$ & $1076(50.6)$ & $311(47.7)$ & $702(47.8)$ & $104(39.7)$ & $66(28.7)$ & $621(42.2)$ \\
\hline $\begin{array}{l}\text { AOR } \dagger \text { of having recently had HIV test } \\
(95 \% \mathrm{CI})\end{array}$ & 1 & $\begin{array}{l}0.81(0.71 \text { to } \\
0.93)\end{array}$ & $\begin{array}{l}0.94 \text { ( } 0.77 \text { to } \\
1.15)\end{array}$ & $\begin{array}{l}0.85 \text { ( } 0.73 \text { to } \\
0.99)\end{array}$ & $\begin{array}{l}1.45 \text { (1.11 to } \\
1.91)\end{array}$ & $\begin{array}{l}1.87(1.41 \text { to } \\
2.48)\end{array}$ & $\begin{array}{l}1.31(1.13 \text { to } \\
1.52)\end{array}$ \\
\hline
\end{tabular}

*Recent HIV testing includes all men tested in the calendar year of the survey and the calendar year before the survey (eg, for the 2005 survey, all men tested in 2004 and 2005 are included in the recent testers category). †Adjusted odds ratio (AOR) of having had a recent HIV test by year of survey, adjusted for age.

2005, and correspond with the Scottish Government policy change to routine, opt-out testing in GUM clinics, which was introduced in the Scottish sexual health strategy. ${ }^{5}$ However, with increasing testing rates over time and a corresponding increase in recent testing, one might have expected to find higher proportions of those who have had a test, to have had one recently, but this was not the case. This, combined with the consistent trend that older age is associated with decreased likelihood of recent testing, is consistent with HIV testing being a one-off event. It is not indicative of HIV testing being a "routine" part of a sexual health check-up.

There are some limitations to consider when interpreting our results. This was a bar-based sample, so only men who visit the venues surveyed had the opportunity to participate and caution should be taken when generalising to the wider population of gay men. The analyses are also limited to the available variables included in all seven surveys; preventing the exploration of other potential confounding factors. Furthermore, our measure

Table 4 Recent HIV testing by reported number of UAI partners in the previous year and age of respondents

\begin{tabular}{lccccc}
\hline & \multicolumn{1}{c}{ Age group } & & & \\
\cline { 2 - 6 } & $\begin{array}{l}\mathbf{2 5} \text { Years } \\
\mathbf{N}=\mathbf{2 0 9 0} \\
\mathbf{n}(\%)\end{array}$ & $\begin{array}{l}\mathbf{2 5 - 3 4} \text { Years } \\
\mathbf{N}=\mathbf{3 4 4 3} \\
\mathbf{n}(\%)\end{array}$ & $\begin{array}{l}\mathbf{3 5 - 4 4} \text { Years } \\
\mathbf{N}=\mathbf{2 0 3 3} \\
\mathbf{n}(\%)\end{array}$ & $\begin{array}{l}\mathbf{4 5 +} \text { Years } \\
\mathbf{N}=\mathbf{7 3 9} \\
\mathbf{n}(\%)\end{array}$ & $\begin{array}{l}\text { Total } \\
\mathbf{N}=\mathbf{8 3 0 5} \\
\mathbf{n}(\%)\end{array}$ \\
\hline $\begin{array}{l}\text { No of UAI partners in previous year } \\
\text { 0/1 Partner }\end{array}$ & & & & & \\
$\quad$ Had recent HIV test* & $539(29.8)$ & $870(28.4)$ & $407(22.1)$ & $131(19.5)$ & $1947(26.3)$ \\
Last tested $>1-5$ years ago & $162(9.0)$ & $616(20.1)$ & $377(20.4)$ & $98(14.6)$ & $1253(17.0)$ \\
Last tested 6+ years ago & $13(0.7)$ & $212(6.9)$ & $263(14.3)$ & $106(15.8)$ & $594(8.0)$ \\
Never had HIV test & $1093(60.5)$ & $1369(44.6)$ & $796(43.2)$ & $337(50.1)$ & $3595(48.7)$ \\
2+ Partners & & & & & \\
$\quad$ Had recent HIV test* & $116(41.0)$ & $172(45.7)$ & $65(34.2)$ & $26(38.8)$ & $379(41.4)$ \\
Last tested $>1-5$ years ago & $27(9.5)$ & $69(18.3)$ & $36(18.9)$ & $13(19.4)$ & $145(15.8)$ \\
Last tested 6+ years ago & $0(0)$ & $19(5.1)$ & $27(14.2)$ & $6(9.0)$ & $52(5.7)$ \\
Never had HIV test & $140(49.5)$ & $116(30.9)$ & $62(32.6)$ & $22(32.8)$ & $340(37.1)$ \\
\hline
\end{tabular}

*Recent HIV testing includes all men tested in the calendar year of the survey and the calendar year before the survey (eg, for the 2005 survey, all men tested in 2004 and 2005 are included in the recent testers category). UAl, unprotected anal intercourse. 
of recent testing would not necessarily pick up all those who had had their first test between studies, given that the gaps between the larger surveys are at least 2 years. However, our findings still have considerable implications for HIV testing and prevention policies.

UK guidelines recommend routine, opt-out HIV testing in GUM settings, ${ }^{717}$ and the offer of HIV testing to MSM in UK clinics increased by 35\% between 2003 and 2006, with uptake reported to be $85 \%{ }^{2}$ However, at the community level in Scotland these changes have not yet achieved the near-universal testing seen in the USA and Australia. ${ }^{12}{ }^{13}$ It is possible that the increase in uptake in GUM clinics reflects more frequent testing in these settings rather than an increase in the absolute numbers of MSM being tested. This is appropriate given that in the community-based surveys of HIV prevalence the majority of men with undiagnosed HIV had previously tested negative, whereas levels of HIV were low among men who have never tested. ${ }^{18}$ Specialist sexual health services are ideally placed to target and recall men who test negative, but report high-risk sexual behaviour, for repeat testing. However, community, or scene-based, testing initiatives should also be trialled to increase testing uptake among men not accessing mainstream services. ${ }^{19} 20$

HIV testing levels among gay men in Scotland could also be limited by factors specific to the Scottish context. In-depth research on the HIV testing behaviour of gay men in Scotland has demonstrated that fear of a positive result, along with HIVrelated stigma and discrimination within the gay community, discouraged testing. ${ }^{14} 2122$ In fact, within this particular cultural context the anticipated burden of coping with a positive diagnosis was understood to be more important in shaping testing decisions than accessing appropriate treatment and care. $^{23}$

Our findings suggest that few men become regular or repeat testers. As would be expected, older men are more likely to have tested within their lifespan, but they are less likely than their younger counterparts to report recent testing. This may indicate that men are making informed decisions about the need to test based on their perceived risk or that there are age-related patterns in undiagnosed infection. Recent testing rates were higher among men who reported high-risk sexual behaviour, but even here under half of men (and only one-third of men aged 35-44 years) who reported UAI with multiple partners in the previous year had had a recent test. The limitations of serosorting (only having UAI with partners of the same status) as a risk-reduction strategy for HIV-negative and untested men have been widely reported, ${ }^{18}{ }^{24-27}$ and men who have never, or

\section{Key messages}

- HIV testing increased among gay men in Scotland between 1996 and 2005 , from $49.7 \%$ to $57.8 \%$, with recent testing increasing from $28.4 \%$ to $33.2 \%$.

- The increase corresponds with the policy change to routine, opt-out testing in GUM clinics, but rates still compare unfavourably with near-universal levels elsewhere.

- Recent testing rates did not increase among ever testers and decreased with age, suggesting few men test repeatedly or regularly.

- Further efforts to increase regular HIV testing among gay men are essential, and must also challenge HIV stigma and "normalise" testing at the community level. not recently, tested cannot claim to know their status accurately if, as described here, they also report sexual risk behaviour. Receptive UAI, particularly with partners of unknown HIV status, is one of the main sexual behaviours identified as a risk factor for HIV seroconversion, ${ }^{28}{ }^{29}$ and therefore accurate knowledge of HIV status is essential if men are to avoid unknowingly putting others at risk of HIV.

Knowledge of HIV status is particularly important when levels of undiagnosed HIV infection are high. Recent data (measured through oral fluid samples collected and anonymously tested for HIV antibodies) show $48.1 \%$ of HIV-positive men in bar-based surveys in Glasgow, and 36.4\% in Edinburgh, are undiagnosed. ${ }^{18}$ The proportion undiagnosed decreases with age, but with higher overall prevalence in older men, the prevalence of undiagnosed HIV is twice as high in older than younger men in community-based surveys (average of $4.5 \%$ in the $26-35$ and $1.9 \%$ in the $15-25$ years age group). ${ }^{18}$ Given that among UK MSM, HIV diagnoses remains highest in the 25-34 and $35-44$ years age groups, ${ }^{2}$ there is a clear need to promote regular HIV testing further.

Testing and treatment decisions are complex, ${ }^{30}$ but early diagnosis is essential to ensure timely access to treatment. In 2006, 20\% of MSM diagnosed with HIV had a CD4 cell count less than 200 cells $/ \mathrm{mm}^{3}$ (which at the time was the recommended threshold for treatment to commence), and men diagnosed late are 14 times more likely to die within a year of diagnosis than those diagnosed earlier. ${ }^{2}$ Nevertheless, efforts to increase regular HIV testing have to promote the positive benefits of knowing your HIV status beyond simply having access to treatment.

Accurate knowledge of status allows men to make effective use of primary and secondary prevention strategies, such as serosorting and postexposure prophylaxis. It should also allow them to make informed sexual risk decisions and be better able to negotiate sex through effective status disclosure, to avoid unknowingly putting others at risk of HIV. However, we have previously demonstrated that gay men in Scotland exhibit undue confidence that their partners share the same assumed negative status as themselves, ${ }^{15}$ and, as previously noted in this paper, there are continuing issues around HIV stigma and discrimination within the gay community. ${ }^{14} 21$ These remain significant barriers to efforts to increase HIV testing further among gay men in Scotland.

Increasing testing may not be enough in itself to reduce HIV infections among UK gay men, when sexual risk is reportedly higher among men living with diagnosed HIV, ${ }^{18}$ but the promotion of regular HIV testing should be an essential component of HIV prevention, and additional, innovative efforts are required to increase its uptake. These efforts must do as much to challenge HIV stigma and "normalise" regular testing at the community level as they do to increase uptake at the individual level.

Acknowledgements: The authors would like to thank the survey staff and fieldworkers in each city, the venue managers, their staff and the men who agreed to participate in the survey.

Funding: The UK Medical Research Council funded the 1996, 1999, 2002a and 2005 surveys as part of the Sexual and Reproductive Health Programme (WBS

U.1300.00.005) at the Social and Public Health Sciences Unit. Healthy Gay Scotland funded the 2000, 2002b and 2003 surveys.

\section{Competing interests: None.}

Ethics approval: Ethics approval was granted for the 1996, 1999, 2002a and 2005 surveys by the University of Glasgow Ethics Committees for Non-clinical Research Involving Human Subjects, and for the 2000 survey by the Psychology Ethics Committee at Glasgow Caledonian University. 
Contributors: PF had the initial idea for the paper and all authors contributed to the interpretation of the data and development of the paper. CK conducted the analyses and LMW wrote the first draft. All authors contributed to subsequent drafts and approved the final version of the manuscript. The 1996 and 1999 surveys were designed and conducted by GJH and PF, the 2002a and 2005 surveys by GJH and LMW and the 2000, 2002b and 2003 surveys by PF.

Provenance and peer review: Not commissioned; externally peer reviewed.

\section{REFERENCES}

1. Elford J. Changing patterns of sexual behaviour in the era of highly active antiretroviral therapy. Curr Opin Infect Dis 2006;19:26-32.

2. The UK Collaborative Group for HIV and STI Surveillance. Testing times: HIV and other sexually transmitted infections in the United Kingdom: 2007. London: Health Protection Agency, Centre for Infections, 2007.

3. Health Protection Scotland. HIV infection and AIDS: quarterly report to 30 September 2008/HIV prevalence among noninjecting drug using heterosexuals, injecting drug users (IDUs), and men who have sex with men (MSM) who undergo attributable HIV testing in Scotland: 2007 update/Unlinked anonymous HIV testing of genito-urinary medicine clinic attendees in Glasgow: data to 2007. HPS Wkly Rep 2008;42:403-16.

4. Williamson LM, Hart GJ. HIV prevalence and undiagnosed infection among a community sample of gay men in Scotland. J Acquir Immune Defic Syndr 2007:45:224-30.

5. Scottish Executive. Respect and responsibility: strategy and action plan for improving sexual health. Edinburgh: Scottish Executive, 2005.

6. Department of Health. The national strategy for sexual health: better prevention, better services, better sexual health. London: Department of Health, 2001

7. British HIV Association, British Association for Sexual Health and HIV, British Infection Society. UK national guidelines for HIV testing 2008. London: British HIV Association, 2008.

8. Centers for Disease Control and Prevention. Revised recommendations for HIV testing of adults, adolescents, and pregnant women in health-care settings. MMWR Morb Mort Wkly Rep 2006;55:1-16.

9. Chief Medical Officer. Improving the detection and diagnosis of HIV in non-HIV specialities including primary care. http://www.dh.gov.uk/prod_consum_dh/groups/ dh_digitalassets/@dh/@en/documents/digitalasset/dh 082338.pdf laccessed 17 August 2009).

10. Bochow MJ, Chiarotti F, Davies P, et al. Sexual behaviour of gay and bisexual men in eight European countries. AIDS Care 1994;6:533-49.

11. Williamson LM, Dodds JP, Mercey DE, et al. Increases in HIV-related sexual risk behaviour among community samples of gay men in London and Glasgow: how do they compare? J Acquir Immune Defic Syndr 2006;42:238-41.

12. Centers for Disease Control and Prevention. Human immunodeficiency virus (HIV) risk, prevention, and testing behaviours - United States, National HIV Behavioural Surveillance System: men who have sex with men, November 2003April 2005. MMWR Morb Mort Wkly Rep 2006;55:1-16.
13. Prestage G, Jin F, Zablotska IB, et al. Trends in HIV testing among homosexual and bisexual men in eastern Australian states. Sexual Health 2008;5:119-23.

14. Flowers $\mathbf{P}$, Knussen $\mathbf{C}$, Church $\mathrm{S}$. Psychosocial factors associated with HIV testing amongst Scottish gay men. Psychol Health 2003;18:739-52.

15. Hart GJ, Williamson LM. Increase in HIV sexual risk behaviour in gay men in Scotland, 1996-2002: Prevention failure? Sex Transm Infect 2005;81:367-72.

16. O'Donnell S. HIV testing in Edinburgh and the Lothians. Final report. Edinburgh: Testing Barriers Project, Gay Men's Health, 2004.

17. Rogstad KE, Palfreeman A, Rooney G, et al. United Kingdom national guideline on HIV testing 2006: Clinical Effectiveness Group, British Association for Sexual Health and HIV. http://www.bashh.org/documents/63/63.pdf laccessed 12 August 2008).

18. Williamson LM, Dodds J, Mercey DE, et al. Sexual risk behaviour and knowledge of HIV status among community samples of gay men in the UK. AIDS 2008;22:1063-70.

19. Huebner DM, Binson D, Woods WJ, et al. Bathhouse-based voluntary counseling and testing is feasible and shows preliminary evidence of effectiveness. $J$ Acquir Immune Defic Syndr 2006;43:239-46.

20. Prost A, Chopin M, McOwan A, et al. "There is such a thing as asking for trouble": taking rapid HIV testing to gay venues is fraught with challenges. Sex Transm Infect 2007;83:185-8.

21. Flowers $\mathbf{P}$, Duncan B, Frankis JS. Community, responsibility and culpability: HIV risk management amongst Scottish gay men. J Commun App/ Soc Psychol 2000;10:258-300.

22. Flowers $\mathbf{P}$, Duncan B, Knussen $\mathbf{C}$. Re-appraising HIV testing: an exploration of the psychosocial costs and benefits associated with learning one's HIV status in a purposive sample of Scottish gay men. Br J Health Psychol 2003;8:179-94.

23. Flowers $\mathbf{P}$, Church $\mathrm{S}$. To test or not? HIV antibody testing amongst gay men. Cult Health Sex 2002;4:43-65.

24. Butler DM, Smith DM. Serosorting can potentially increase HIV transmissions. AIDS 2007:21:1218-20.

25. Eaton LA, Kalichman SC, Cain DN, et al. Serosorting sexual partners and risk for HIV among men who have sex with men. Am J Prev Med 2007;33:479-85.

26. Elford J, Bolding G, Sherr L, et al. No evidence of an increase in serosorting with casual partners among HIV-negative gay men in London, 1998-2005. AIDS 2007:21:243-5.

27. Mao L, Crawford JM, Hospers HJ, et al. 'Serosorting' in casual anal sex of HIVnegative gay men is noteworthy and is increasing in Sydney, Australia. AIDS 2006;20:1204-6.

28. Koblin BA, Husnik MJ, Colfax G, et al. Risk factors for HIV infection among men who have sex with men. AIDS 2006;20:731-9.

29. Macdonald N, Elam G, Hickson F, et al. Factors associated with HIV seroconversion in gay men in England at the start of the 21st century. Sex Transm Infect 2008;84:8-13.

30. Flowers $\mathbf{P}$, Knussen $\mathrm{C}$, Duncan B. Re-appraising HIV testing among Scottish gay men: the impact of new HIV treatments. J Health Psychol 2001;6:665-78. 